\title{
BMJ Open Validation of risk assessment scales and predictors of intentions to quit smoking in Australian Aboriginal and Torres Strait Islander peoples: a cross-sectional survey protocol
}

\author{
Gillian Sandra Gould, ${ }^{1,2}$ Kerrianne Watt, ${ }^{3}$ Andy McEwen, ${ }^{4}$ Yvonne Cadet-James, ${ }^{5}$ \\ Alan R Clough ${ }^{6}$
}

To cite: Gould GS, Watt K, McEwen $A$, et al. Validation of risk assessment scales and predictors of intentions to quit smoking in Australian Aboriginal and Torres Strait Islander peoples: a crosssectional survey protocol. BMJ Open 2014;4:e004887. doi:10.1136/bmjopen-2014004887

- Prepublication history and additional material is available. To view please visit the journal (http://dx.doi.org/ 10.1136/bmjopen-2014004887).

Received 19 January 2014 Revised 14 May 2014 Accepted 20 May 2014

CrossMark

For numbered affiliations see end of article.

Correspondence to Dr Gillian Sandra Gould; gillian.gould1@my.jcu.edu.au

\section{ABSTRACT}

Introduction: Tobacco smoking is a very significant behavioural risk factor for the health of Australian Aboriginal and Torres Strait Islanders, and is embedded as a social norm. With a focus on women of childbearing age, and men of similar age, this project aims to determine how Aboriginal and Torres Strait Islander smokers assess smoking risks and how these assessments contribute to their intentions to quit. The findings from this pragmatic study should contribute to developing culturally targeted interventions.

Methods and analysis: A cross-sectional study using quantitative and qualitative data. A total of 120 Aboriginal and Torres Strait Islander community members aged $18-45$ years will be recruited at community events and through an Aboriginal Community Controlled Health Service (ACCHS). Participants will be interviewed using a tablet computer or paper survey. The survey instrument uses modified risk behaviour scales, that is, the Risk Behaviour Diagnosis (RBD) scale and the Smoking Risk Assessment Target (SRAT) (adapted from the Risk Acceptance Ladder) to determine whether attitudes of Aboriginal and Torres Strait Islander smokers to health risk messages are predictors of intentions to quit smoking.

The questionnaire will be assessed for face and content validity with a panel of Indigenous community members. The internal consistency of the RBD subscales and their patterns of correlation will be explored. Multivariate analyses will examine predictors of intentions to quit. This will include demographics such as age, gender, nicotine dependence, household smoking rules and perceived threat from smoking and efficacy for quitting. The two risk-assessment scales will be examined to see whether participant responses are correlated.

Ethics and dissemination: The Aboriginal Health \& Medical Research Council Ethics Committee and university ethics committees approved the study. The results will be published in a peer-reviewed journal and a community report will be disseminated by the ACCHS, and at community forums.
Strengths and limitations of this study

- First study on risk assessment scales in the target population.

- Unique approach to smoking in Aboriginal and Torres Strait Islander peoples of childbearing age.

- Draws on well-established and new measures.

- Potential limitations relate to information and selection biases.

Note about terminology: We use the term Aboriginal and Torres Strait Islander peoples, except where previous research has reported findings from only one group for example, Aboriginal people. Indigenous is used here to refer to Indigenous peoples in the international context, and issues, policies or systems, for example, Indigenous health, Indigenous tobacco control.

\section{INTRODUCTION}

Australia claims one of the lowest rates of $15.1 \%$ of tobacco smoking in Organisation for Economic Cooperation and Development countries. ${ }^{1}$ However, several subgroups of the population maintain high rates of smoking. ${ }^{2}$ Tobacco smoking is the main preventable risk factor contributing to the burden of disease in Aboriginal and Torres Strait Islander peoples. ${ }^{3}$ While there has been a significant drop in Indigenous smoking prevalence over the last 10 years overall, smoking rates are 2.6 times that of the general population at $41 \%$, with higher rates of $50 \%$ or more in remote areas. ${ }^{45}$ However, prevalence of Indigenous smoking in the age group 25-34 years has not decreased significantly for either gender, ${ }^{4}$ and rates in pregnant Aboriginal and Torres Strait Islander 
women are quadruple (49.3\%) those of pregnant women in the general population $(12.1 \%){ }^{6}$

While it is acknowledged that Indigenous populations across and even within different continents belong to very diverse communities with their own cultures and norms, some broad factors impact on Indigenous peoples in colonised Western nations. American Indians, Alaskan Natives, New Zealand (NZ) Māori and Inuit all have a higher prevalence of smoking than the mainstream populations, ${ }^{7}$ particularly in their reproductive years, resulting in significant health disparities. ${ }^{8}$ Smoking is comparably affected by the social determinants of health, and cultural factors, including for some First Nation peoples ceremonial and spiritual uses of tobacco. ${ }^{9}$ Aboriginal and Torres Strait Islander peoples have a long history of tobacco use. ${ }^{10}$ It is believed that the effects of colonisation, ${ }^{10}$ the stolen generation ${ }^{11}$ and racism ${ }^{12}$ have all contributed to the contemporary use of tobacco, to the detriment of the health and longevity of Aboriginal and Torres Strait Islander peoples and their future generations. Factors promoting smoking and smoking initiation in Aboriginal and Torres Strait Islander peoples include community and family norms of smoking, ${ }^{13}$ smoking to promote social inclusiveness and cohesion, ${ }^{14}$ peer group belonging ${ }^{15}$ and daily stressors. $^{13}$

Several studies have explored the knowledge levels of Aboriginal and Torres Strait Islander peoples about tobacco smoking, ${ }^{16-18}$ with more limited exploration about Indigenous attitudes and beliefs about the risks of smoking. There has been some exploration about what antismoking messages are effective and acceptable for Aboriginal and Torres Strait Islander populations, ${ }^{19}$ as media messages or as adjuncts to clinical treatment. ${ }^{20}$ Mainstream antismoking campaigns have shown to be effective in terms of recall and perceived effectiveness by Indigenous peoples in Australia, ${ }^{21} 22$ the $\mathrm{USA}^{23}$ and $\mathrm{NZ},{ }^{24}$ but have not necessarily translated into increased quit rates in these populations. ${ }^{25}$ Aboriginal and Torres Strait Islander smokers in a forced exposure to several television advertisements rated those containing strong graphic imagery or personal narratives as effective for a range of measures including being more likely to quit. ${ }^{19}$ Indigenous peoples in the USA, Australia and NZ have a preference for culturally targeted campaigns. ${ }^{25}$ Aboriginal and Torres Strait Islander viewers aged 1640 years of the 'Break The Chain' campaign in Australia positively rated the targeted advertisement, had good recall and 57\% stated they intended to quit in the following month. ${ }^{26}$ Where culturally targeted campaigns have been tested, alongside generic campaigns, for example, in NZ youth, they proved as effective at supporting Maori to quit smoking as generic messages were for the general NZ population. ${ }^{27}$

However, attitudes of Indigenous maternal smokers, to prevailing health risk messages about smoking, have been under-researched. A systematic review used meta-ethnography to synthesise the evidence on the knowledge, attitudes and experiences of maternal smoking by Aboriginal and Torres Strait Islander peoples, ${ }^{13}$ from seven studies. ${ }^{14}{ }^{28-33}$ The synthesis revealed a lack of salience of media messages and potentially some resistance to advice. ${ }^{13}$ Equally pregnant women have highly protective attitudes towards babies and children. ${ }^{13}$ A recent study of attitudes of maternal Aboriginal smokers and their family members suggested that attitudes about the health risks of smoking may be influenced by messages not matching the women's lived experiences, coupled with inadequate access to information. ${ }^{34}$ Limited knowledge about the specific hazards of smoking and cessation, ${ }^{35}$ and the lack of salience of antismoking messages are barriers to effective cessation. ${ }^{13}$ However, a programme using a culturally targeted smoking cessation video with pregnant Alaskan Native smokers was no more efficacious than in the control group. ${ }^{36}$ Issues less well understood are how Indigenous adults broadly assess their risks in relation to tobacco smoking (not just their knowledge of adverse health effects) and how these assessments are related to their intentions to quit smoking. If attitudes to risk-taking behaviour for smoking and responses to antitobacco messages are not understood it is difficult to formulate effective messages and interventions. There are no best practice guidelines to develop and personalise such messages for Aboriginal and Torres Strait Islander peoples. ${ }^{20} 3738$

Our study therefore aims to determine how Aboriginal and Torres Strait Islander smokers of childbearing age assess risks about tobacco smoking and how these assessments are associated with their intentions to quit smoking or seeking help to quit. We further aim to determine which demographic and behavioural factors (such as age, gender, nicotine dependence level, household smoking rules) are predictors of intentions to quit and seek help for quitting. Two risk assessment scales for smoking will be examined for their cultural acceptability, validity and reliability, and their utility as a pragmatic heuristic.

\section{Underpinning theories}

Research shows that interventions based on the assessment of risk behaviour can positively influence the risktaking behaviour that contributes to a range of preventable diseases. ${ }^{39}$

Witte et $a t^{40}$ proposed a theory called the Extended Parallel Process Model (EPPM) to explain message processing and subsequent behavioural intentions (Key constructs shown in table 1).

According to the EPPM, "when people perceive a serious and relevant threat, they become scared', (ref. 40, p. 318) and will take an action to reduce their fear by one of two general pathways. People can either control the danger elicited by the threat by making a positive and conscious shift in attitude and behaviour (called protective motivation or danger control responses). Alternately they may feel fearful and try and 
Table 1 Key constructs, definitions and measures (adapted from Witte et $a f^{40}$ )

\begin{abstract}
Definitions of constructs
Perceived threat: awareness of a specific harm in the environment, consisting of

Susceptibility to threat: belief about one's risk of experiencing the threat

Severity of threat belief about the magnitude of the threat Perceived efficacy: thoughts about ease, feasibility and the effectiveness of averting the threat, consisting of

Self-efficacy: belief in one's ability to perform recommended response

Response efficacy: belief about effectiveness of recommended response to avert the threat

Danger control dominance: the dominant response in the person faced with a threat, who considers themselves able to perform the recommended response, believes the response to be effective, therefore tries to reduce the danger by taking positive action (protective motivation)

Danger control responses (protective motivation): beliefs, attitudes, intentions, and behaviour changes in accordance with the message recommendations

Fear control dominance: the dominant emotional response in the person when faced with a threat, who feels unable to perform the recommended response and/or believes the response to be ineffectual, and tries to psychologically reduce their fear by defensive motivation

Fear control responses (defensive motivation): coping responses that diminish fear

Critical point: when perceptions of threat begin to outweigh perceptions of efficacy, causing shift from danger control to fear control processes

Discriminating value: a numerical value used to discriminate between people in danger vs fear control
\end{abstract}

Protective responses: similar to danger control responses, but beliefs/attitudes are centred around protecting others from tobacco smoke

\section{How measured on RBD scale or other}

Total of perceived threat scores

Subtotal of susceptibility scores

Subtotal of severity scores

Total of perceived efficacy scores

Subtotal of self-efficacy scores

Subtotal of response efficacy scores

High-efficacy score and high-threat score

Score from intentions to quit/seek help scales (Wong and Cappella) and responses to MTSS questions

Low-efficacy score with high-threat score

Score from questions about defensive avoidance, denial, reactance, message derogation and perceived manipulation The exact critical point can vary with topics and populations

Formula: ( $\sum$ perceived efficacy $)-\left(\sum\right.$ perceived threat $)$ =discriminating value

A positive score indicates danger control processes; a negative score indicates fear control processes

Score from 5 new measures to attitudes about smoking exposure for Aboriginal or Torres Strait Islanders, babies and children

RBD, risk behaviour diagnosis; MTSS, motivation to stop smoking; $\Sigma$, sum of.

control the fear unconsciously by denial, discounting or reactance against the threat (called defensive motivation or fear control responses). If people feel no threat at all (perhaps due to a lack of knowledge) there may be a low response to the message. Furthermore Witte et at $t^{40}$ has shown that that the level of perceived efficacy determines whether people engage in danger control or fear control responses.

Witte et $a l^{40}$ devised and validated a scale called the Risk Behaviour Diagnosis (RBD) scale to measure these responses across four dimensions of perceived threat (perceived susceptibility and severity of threat) and perceived efficacy (response efficacy and self-efficacy). High-threat responses coupled with high efficacy tend to lead to danger control responses, in this case to adopt message recommendations, change attitudes, intentions and smoking behaviour. In contrast, if people feel they cannot adopt the recommended response to avert the threat, because of a lack of efficacy (it is too hard, too little support or it is perceived as futile to do so), they typically try to control the fear by avoiding the issue, discount the message or may consider the issue is exaggerated.

If fear control processes are initiated, it can be difficult to shift attitudes and there is a need for carefully constructed messages to 'break through defence mechanisms'. ${ }^{41}$ Therefore, according to this theory people who are in fear control will need assistance to build up efficacy rather than make them more fearful. Bandura's work on self-efficacy confirms this and he considers self-efficacy is central to any healthy behaviour change. ${ }^{42}$

The EPPM model is a predominant message design theory, ${ }^{43}$ and has been widely applied to a range of health behaviours internationally and a wide range of health promotional campaigns, and is the basis of tobacco counter marketing. ${ }^{39}$ A study by Wong and Cappella ${ }^{44}$ has used the RBD to measure responses to video-based antitobacco 
television advertisements. Assessment scales for risk behaviour, including the RBD, have been used in several minority groups and across cultures. ${ }^{45-53}$ However, risk assessment scales for tobacco and the EPPM have not been used or validated for Australian Aboriginal or Torres Strait Islander or other Indigenous populations.

Another theory informing this study is PRIME theory (P-plans; R-responses; I-impulses; M-motives; E-evaluations), which proposes that smokers' motivations are fluid and can change unexpectedly. ${ }^{54}$ The central tenets of PRIME theory include people's wants and needs in the moment, and their self-identity. ${ }^{54}$ West $^{55}$ suggests that a person can be stimulated to make a quit attempt, even if they have not been thinking about quitting, especially if the intervention is repeated and evidence-based therapy offered. A new measure based on PRIME theory, called the risk acceptance ladder $(\text { RAL })^{56}$ (Cattaruzza and West, 2014, in preparation) proposes that the blocks to effective behaviour change can be ascertained by determining the individual level of risk acceptance and at what stage motivation has been stalled. For this study the RAL is modified into the Smoking Risk Assessment Target (SRAT; see methods). If this measure correlates well with message processing it may be also useful to assess Aboriginal and Torres Strait Islander smokers.

\section{Rationale for assessing validity and reliability of the} scales for Aboriginal and Torres Strait Islander smokers

Assessment scales, developed for Western populations, are important to validate before use in a cross-cultural context. ${ }^{57}$ Theoretical concepts developed in the context of the dominant Western psychology and communication fields may not transfer into a cross-cultural or Indigenous setting. ${ }^{57}$ Preliminary phases of community engagement are an important part of the process of validation, and will be described below. ${ }^{58}$ Results from the validation and reliability process also need careful interpretation with culturally competent advisors. ${ }^{58}$

\section{METHODS AND ANALYSIS \\ Study overview}

This is a cross-sectional study to investigate the validity and reliability of risk assessment scales, and predictors of intentions to quit smoking, for Australian Aboriginal and Torres Strait Islander smokers of both genders, aged 18-45 years old. The study will be conducted through face-to-face interviews in a regional centre in New South Wales (NSW) Australia.

\section{Research questions}

1. Are RBD/SRAT and associated measures of tobacco behaviour reliable and valid in Australian Aboriginal and Torres Strait Islander smokers?

2. What are the main predictors of intentions to quit smoking and intentions to seek help for quitting in Aboriginal and Torres Strait Islander smokers?
3. What variables confound the associated factors and intentions to quit and to seek help in Aboriginal and Torres Strait Islander smokers?

4. What smoking-related attitudes (eg, danger/fear control responses) are associated with positive/negative discriminating values on the RBD?

5. What are the associations between the RBD and SRAT?

\section{Study population}

\section{Participant recruitment and setting}

The study site is a regional centre in NSW. Recruitment into the study will be by personal intercept, primarily at regional community and social events and in other settings likely to yield interest, including a local Aboriginal Community Controlled Health Service (ACCHS). The survey will be administered by face-to-face interview, using where possible a tablet computer, connected by cellular network to a secure on-line survey site. Where connectivity is unreliable a paper survey will be used and data submitted on-line later. The interviewers will be either the first author (non-Indigenous female) or Indigenous research assistants or ACCHS staff.

Aboriginal and/or Torres Strait Islander people, aged $18-45$ years old who currently smoke will be included in the study, if they self-report as Indigenous and are in the age bracket. Although we would have preferred to include participants under 18 years, the ethics committee did not support this. Participants will be offered a $\$ 10$ shopping voucher for their time.

\section{Sample size calculation}

The estimated sample size is 120 participants. Sample size estimations are based on the procedure described by Altman. ${ }^{59}$ Standardised differences for intention to quit smoking and intention to seek help to quit smoking are calculated using means (M) and SDs published by Wong and Cappella $^{44}$ (intent to quit M 2.48, SD 0.78; intent to seek help M 1.85, SD 0.77). These figures are taken from a different population because there have been no relevant studies in Indigenous peoples. A total sample size of 110 is required to detect a significant difference between people in 'danger control' versus people in 'fear control' (according to the RDB scale) and intentions to quit smoking, at $\alpha<0.05$, and $90 \%$ power. An additional sample size calculation was performed to determine the required sample size to detect prevalence of knowledge, attitudes and behaviour within the target population. The required sample size is 100 , based on $50 \%$ prevalence, $10 \%$ precision and $95 \%$ CIs. However, for the multivariate analysis 120 participants are required (assuming 6 key variables). ${ }^{60}$

\section{Sampling stratification}

Random sampling will not be feasible. To ensure that the convenience sample is as representative of the target group as possible, the sample will be stratified by age group and gender. Data from the 2011 Australian 
Table 2 Stratified sampling strategy of target Aboriginal and Torres Strait Islander populations

\begin{tabular}{|c|c|c|c|c|c|c|c|c|}
\hline \multirow[b]{2}{*}{$\begin{array}{l}\text { Age range } \\
\text { (years) }\end{array}$} & \multicolumn{2}{|c|}{$\begin{array}{l}\text { Target populations } \\
\text { numbers ( } 2011 \\
\text { Census from } \\
\text { regional city LGA) }\end{array}$} & \multicolumn{2}{|c|}{$\begin{array}{l}\text { Smoking prevalence } \\
\text { (2008 NATSISS) }\end{array}$} & \multicolumn{2}{|c|}{$\begin{array}{l}\text { Per cent of target populations } \\
\text { in regional city who smoke }\end{array}$} & \multicolumn{2}{|c|}{$\begin{array}{l}\text { Sample } \\
\text { stratified by } \\
\text { gender and age } \\
\text { group }\end{array}$} \\
\hline & $\begin{array}{l}\text { Male } \\
\mathbf{N}\end{array}$ & $\begin{array}{l}\text { Female } \\
\mathbf{N}\end{array}$ & Male (\%) & Female (\%) & $\begin{array}{l}\text { Male } \\
\mathrm{N}(\% \text { of total) }\end{array}$ & $\begin{array}{l}\text { Female } \\
\mathrm{N}(\% \text { of total) }\end{array}$ & $\begin{array}{l}\text { Male } \\
\mathbf{N}\end{array}$ & $\begin{array}{l}\text { Female } \\
\mathbf{N}\end{array}$ \\
\hline $18-24$ & 172 & 178 & 38.7 & 39.7 & 67 (13.9) & $71(14.7)$ & 17 & 18 \\
\hline $25-34$ & 142 & 184 & 56 & 50.1 & $80(16.6)$ & 92 (19) & 20 & 23 \\
\hline $35-44$ & 154 & 187 & 55.5 & 47.3 & 85 (17.6) & 88 (18.2) & 21 & 22 \\
\hline Total & 468 & 549 & & & $232(48.1)$ & 251 (51.9) & 58 & 63 \\
\hline
\end{tabular}

Census determine the population parameters for persons identified as Aboriginal and/or Torres Strait Islander, by age group and gender in the regional city. The proportion of smokers within each age group and gender are estimated using smoking prevalence data from the 2008 National Aboriginal and Torres Strait Islander Social Survey (table 2). ${ }^{61}$

As can be seen from table 2, the final sample will be 58 males and 63 female smokers $(\mathrm{N}=121)$. This represents $25 \%$ of the Aboriginal and Torres Strait Islander smokers aged 18-45 years in the regional city $(121 / 483)$.

\section{MEASURES/DATA COLLECTION}

\section{The survey}

The survey will collect quantitative data, requiring categorical responses or responses on Likert scales where appropriate, on participants' smoking behaviours, initiation of smoking, attitudes to smoking and cessation, attitudes to health risks of smoking, experiences with quit attempts and smoking cessation and future intentions to quit smoking or seek help for quitting. The questionnaire will also elicit responses about smoking in pregnancy and the protection of babies and children from tobacco smoke. The participants will be asked to rate the level of support available from family and peers for quitting and professional support. Three open-ended questions are used in the survey: (1) to initially explore general attitudes to smoking; (2) to ascertain whether there is any more the participant would like to say about smoking or quitting at the end of the interview; and (3) to elicit more detail from those who indicate that they do not want to quit smoking. The survey guide includes 'notes sections' on most of the pages, so that the interviewer can record relevant comments or narratives expressed by the participant in the course of the interview. The survey was pilot tested with an Aboriginal Health Worker (AHW), and based on this it is anticipated that it will take approximately $20 \mathrm{~min}$ for participants to complete.

\section{The questionnaire includes several instruments Tobacco dependence scales}

Heaviness of Smoking Index (HSI) is an accepted method of assessing nicotine dependence levels, calculated from the time to first cigarette and number of cigarettes smoked per day. Its reliability has been shown to be better than the longer Fagerstrom Test for Nicotine Dependence. ${ }^{62}$

Strength of urges to smoke (SUTS) is another measure of dependence found to be more reliable for predicting cessation than the HSI. ${ }^{62}$ It is a routine part of the 'Smoking in England' survey, administered to over 10000 smokers per annum. ${ }^{63}$ It is a newer scale for nicotine dependence and is included here, as it has not yet been used with Australian Aboriginal and Torres Strait Islander smokers or other Indigenous populations.

\section{Intentions to quit}

The Motivation To Stop Scale (MTSS) uses dichotomous measures (yes/no) for intentions to quit (want to quit, should quit and intends to quit) and has shown good level of prediction for quitting. ${ }^{64}$ Intentions to quit and intentions to seek help (Likert scale) are also adapted from Wong and Cappella. ${ }^{44}$

\section{Risk assessment scales}

The RBD Scale consists of a series of questions (Likert scales) on four aspects: severity of threat, susceptibility to threat, response efficacy and self-efficacy. ${ }^{40}$

As a measure of fear control responses participants will be asked to respond to four questions about reactance, avoidance and message derogation on a Likert scale. ${ }^{40}$ Similarly for danger control responses an aggregate score of the five questions on intentions to change smoking behaviour/seek help will be calculated. ${ }^{44}$ Owing to the evidence pointing to strong protective attitudes in the target population, five questions on a Likert scale will be asked to determine protective responses about smoking in pregnancy, around children and for Aboriginal and Torres Strait Islander peoples in general. A protection score will be calculated from these responses.

The RAL is a new measure currently being used in Italy to research a population with high rates of smoking (Cattaruzza and West, 2014, in preparation). The measure has been adapted to the Aboriginal and Torres Strait Islander populations, as below. 
Consultative process, face validity and questionnaire adaption

In the formative phase of the research, before ethics approvals were finalised, several community consultation processes were conducted. The aim was to test the content and face validity, suitability, readability, cultural appropriateness, acceptability and feasibility of the survey instrument. Consultation was through a focus group with Aboriginal and/or Torres Strait Islander people in the target age group and an Aboriginal elder, recruited from an Aboriginal Studies class at a local tertiary college and two Aboriginal Indigenous student liaison staff from the University campus $(\mathrm{N}=7)$. Several consultative interviews were also held with a senior AHW specialising in tobacco. Expert input was obtained for the scales from their respective inventors, to informally assess whether they maintained integrity once adapted, rather than assess their cultural suitability for this population (Witte-Cattaruzza-West).

The RBD scales were adapted to tobacco-related risks from the templates in Witte's manual (see online supplementary appendix 1). ${ }^{41}$ The community consultation group and AHW requested changes to several questions and suggested additional questions about reasons for smoking initiation. Minor rewording was suggested for some of the RBD core statements to make them more comprehensible to this population. Additionally, several sensitive questions about socioeconomic status and pregnancy were reworded.

The RAL was adapted for the Aboriginal and Torres Strait Islander populations, and was renamed the SRAT as follows:

A. It was deemed more culturally appropriate to depict the measure as a target with concentric circles (progressing from the outside to the centre) instead of a ladder, for the Aboriginal and Torres Strait Islander populations.

B. The potential responses of the SRAT were reworded to become more appropriate for the target population, and two additional responses included (see online supplementary appendix 1 ).

Changes were approved by the HRECs.

\section{ANALYSIS}

Box 1 outlines variables that will be measured.

\section{Statistical analyses}

On study completion, the data entered through the survey software will be used to generate a summary report and exported directly to SPSS V. 20 for analysis. Descriptive analyses will summarise the data for all variables.

To measure the reliability and validity of the scales the following will be used:

1. Content validity and face validity is qualitatively assessed through the community panel and expert consultation for RBD and SRAT.

\section{Box 1 Variables from questionnaire}

Demographics

- Age

- Gender (male/female)

- Aboriginal and Torres Strait Islander status (Aboriginal/Torres Strait Islander/both)

- SES (calculated from postcode, suburb, income source, healthcare card use, education)_for details contact authors

- Environmental variables

A. Number of smokers in household $(1 / 2-3 />3)$

B. Pregnant women in the house $(\mathrm{Y} / \mathrm{N})$

C. Children in the house $(\mathrm{Y} / \mathrm{N})$

D. Complete, partial or no bans for household smoking

E. Smoke free behaviours of participants (house and car)

Smoking behaviour variables

- Nicotine dependence scores (Heaviness of Smoking Index and SUTS)

- Age of smoking initiation and uptake

- Factors influencing smoking initiation (11 response options)

- Patterns of smoking (frequency and type)

- Smoking by others in social circle $(\mathrm{Y} / \mathrm{N})$

- Current/previous quit attempts (Y/N)

- Current/previous use of cessation therapies (Y/N)

- Level of support for quitting (social and professional) (sliding scales 0-10)

Smoking risk-related attitudes

- RBD scale resulting a composite score (discriminating value, recoded positive or negative)

- Threat score (three items for susceptibility plus three for severity of threat on Likert scales of 1-5)

- Efficacy score (three items for response efficacy plus three for self-efficacy on Likert scales of 1-5)

- RBD results recoded into four quadrants of high efficacy/high threat; high efficacy/low threat; low efficacy/high threat; low efficacy/low threat

- Fear control responses score (calculated from questions on avoidance, denial and refuting messages, Likert scales 1-5)

- Danger control responses score (calculated from questions on intentions to quit or seek help, Likert scales 1-5)

- Protective responses score (calculated from questions on attitudes about protecting babies/children, Likert scales 1-5)

- General attitudes about smoking and quitting (13 response options)

- SRAT (choice of 1 option from 12, will be reduced to 4 categories)

Behavioural intentions

- Intentions to quit (MTSS) (want/do not want) - if affirmative then how soon intends to quit (3 month/ 1 month/hope to soon/do not know)

- Intentions to quit or reduce smoking (Wong and Cappella) (Likert scales 1-4)

- Intentions to seek help with quitting (Wong and Cappella) (Likert scales 1-4)

$\mathrm{Y}$, yes; N, no; SUTS, strength of urges to smoke; RBD, risk behaviour diagnosis; SRAT, smoking risk assessment target; MTSS, motivation to stop smoking scale.

2. The patterns of correlation will be explored between the RBD subscale scores (susceptibility and severity of threat, and response and self-efficacy) and also for 
danger control responses, fear control responses and protective responses.

3. Internal consistency of subscales will be assessed with Cronbach's $\alpha$.

Multivariate analyses will seek the most likely demographic predictors of intentions to quit smoking/seek help for quitting, for example, age, gender, dependence levels, household smoking rules. Psychological factors such as threat and efficacy scores, danger and fear control responses will be analysed to assess whether they further influence the outcome measures.

\section{RBD scores and the SRAT will be examined to see whether participant responses are correlated}

Qualitative and open-ended responses will undergo a general inductive thematic analysis, ${ }^{65}$ by two researchers independently. A cut and paste technique will be used for initial coding using Excel spread sheets, and consensus reached by discussion. The themes will be used to enrich the quantitative findings.

\section{ETHICS AND DISSEMINATION}

The study is low risk in terms of ethics; however, discussing smoking may be considered a sensitive issue for Aboriginal and Torres Strait Islander participants, and researchers collecting the data will be suitably briefed. The research will adhere to Australia's National Health and Medical Research Council's Values and Ethics in Aboriginal and Torres Strait Islander Health Research 2003 guidelines, that is, reciprocity, respect, equality, responsibility, survival and protection, spirit and integrity ${ }^{66}$ Examples of reciprocity include the first author sharing her knowledge and skill base (as a general practitioner and tobacco treatment specialist) about tobacco control and research with the participating organisations and their staff members. The participants also would be offered brief advice on smoking cessation if they wished after the interview, and extra resources such as a culturally adapted video. The primary HREC is the Aboriginal Health \& Medical Research Council Ethics Committee (AH\&MRC), which approved the study with support from the partnering ACCHS (approval number 928). Additional HRECs ratified the primary approval (James Cook University (H4467) and Southern Cross University (ECN-13-242)).

Participants will be approached at community events that are targeted at the local Australian Aboriginal and Torres Strait Islander communities. Potential recruits will be asked if they fulfil the selection criteria and canvassed about their willingness to join in the study. All participants will be provided with a participant information sheet advising the purpose of the study and implications regarding:

- Objectives of the research.

- Why the information is being collected and how it will be used, accessed and stored.
- Voluntary nature of the study, provision for withdrawal of consent, assurance of confidentiality and anonymity.

After the information sheet is explained, the participant will be asked to provide informed consent by having their name typed on the touch screen of the tablet computer and ticking the 'agree' box. All data will be deidentified and data and materials will be stored for 7 years, in a secure location where it will be digitally stored, password protected and only accessed by the researchers.

This study is one of several studies contributing to a PhD Public Health thesis for the first author. Journal articles and presentations at relevant national and international conferences to academics, researchers and stakeholders will disseminate these findings. The outcomes of the study will also inform policy and practice recommendations. A community report will be sent to the partnering ACCHS for dissemination to clients at the service and to the communities who have been involved. Community-based forums will be held as appropriate.

\section{DISCUSSION}

This study aims to determine how Australian Aboriginal and Torres Strait Islander smokers of childbearing age assess risks about tobacco smoking and how these assessments are associated with their intentions to quit smoking. We aim to validate two risk assessment scales for Aboriginal and Torres Strait Islander smokers, which could have the potential for research transference to a clinical or public health setting.

The RBD scale was originally designed as a clinical tool to be used in the context of delivering tailored health messages at a clinic for sexually transmitted diseases and HIV testing. ${ }^{40}$ Advice was then adapted to individuals according to their responses.

Primary healthcare practitioners and clinicians are often faced with the task of assisting Aboriginal and Torres Strait Islander smokers to quit smoking. Antitobacco messages do not just lie in the domain of social marketing: they also need to be carefully pitched to maximise receptivity and support behaviour change within the clinical consultation. Little is known about the effectiveness of smoking behaviour change models for Aboriginal and Torres Strait Islander peoples. The trans-theoretical model (or stages of change (SOC)) has been widely used in Australia for Aboriginal and Torres Strait Islander smokers, but outcomes have never been evaluated. ${ }^{67}$ Aboriginal smokers in remote areas have been described as more likely to be in the precontemplative or contemplative stages of change and require more assistance to ready to quit smoking. ${ }^{68}$ Also it is known that motivational interviewing, including that based on the SOC, is not as effective in pregnancy as in the general population ${ }^{69}$ and holds no special advantages over other types of psychosocial counselling. ${ }^{70}$

If the measures under examination here are found to be reliable for the target audiences of Aboriginal and 
Torres Strait Islander smokers of childbearing age, then accurate assessments could be made. A new model based on assessment of risk behaviour could have the potential to assess fear versus danger control responses and facilitate the pitching of tailored antitobacco messages for the individual, build motivational tension for quitting and yet avoid engendering fear control responses or resistance.

If people are engaged in fear control processes, messages developed should focus on the efficacy of the recommended response to counteract the high levels of perceived threat. Focusing on threat messages alone may cause the messages to backfire. It is important to emphasise that the recommended responses are feasible and effective to avert the threat from smoking. It is essential to help people develop a belief in their ability to quit smoking, develop supportive environments for quitting and provide easy access to treatment.

Central to building self-efficacy are strategies recommended by Bandura. ${ }^{42}$ He suggests several approaches: building skills, self-control and mastery for quitting; learning about the experiences of others who have successfully quit; verbal persuasion and motivation; helping people adopt a positive mindset and importantly having access to effective therapies. ${ }^{42}$

Alternatively, if the target audience is in danger control, messages can remind people about the threat of smoking to maintain motivation, while also increasing efficacy for quitting, as above.

People with low threat perceptions may be neither in danger or fear control. They may need to be convinced about the seriousness of or their susceptibility to the threat. This group requires messages aimed at improving knowledge and correcting any misconceptions. This may be best achieved by having messages come from someone who is very similar to the client (possibly through use of tailored videos or personalised narratives).

The SRAT may prove a simplified way to approach risk assessment in this target group, as it demands a single response to a question. The measures require validation for Aboriginal and Torres Strait Islander smokers in this childbearing age bracket, prior to a more formal assessment of feasibility and effectiveness in a clinical setting.

Previous research has demonstrated the strong social and environmental influences on smoking cessation, and the role health professionals play in supporting smoking cessation in Aboriginal and Torres Strait Islander communities. ${ }^{71}$ The study will also assess predictors of intentions to quit that include measures of socioeconomic position, smoking by friends and household members, support offered by family and health professionals and a range of other factors. These measures have the potential to determine social and health profession influences on intentions to quit smoking in this population. The analysis will determine if once these factors are controlled for whether the responses to the risk assessment measures have any additional impact.
Limitations and strengths

The study will be based on a sample from one regional area of NSW, fostering ownership of the project results for the local partnering ACCHS. Australian Aboriginal groups are diverse and this study will be conducted in just one region. It is unknown how many Torres Strait Islanders reside in the area and how many will chose to participate in the study. As the validity and reliability measures to be used are context specific, they should be considered provisional, pending a larger study. These limitations impact on generalisability and transferability of the findings, although this is a pragmatic constraint for all research in diverse Indigenous groups. Selection bias may be operant if only those more willing to talk about their smoking agree to participate, another inevitable challenge for this kind of research. Recruiting some participants through a health service may favour those already with health problems, and who may already have motivation to quit smoking. There could be information biases: smoking status will be based on selfreport and not any objective measures; recall bias may be operant with asking people to recollect their smoking history and perceived level of support for quitting; and social desirability bias with people reporting what they think the researcher wants to hear.

On the other hand, this is the first study as far as we know to validate risk assessment measures for tobacco smoking in a population of Aboriginal and Torres Strait Islander smokers. Health education and behaviour studies are tested for validity and reliability inconsistently, ${ }^{72}$ and very few scales are validated for Aboriginal and Torres Strait Islander populations. ${ }^{73}$ So the study is needed and an important one, although small and specific to one region. The study takes a unique approach to smoking in Aboriginal and Torres Strait Islander peoples of childbearing age by drawing on well-established and new measures from the health communication and addiction fields. If these measures prove to be valid and reliable they have a high potential for research translation into clinical settings. The outcomes could further inform the development and refining of social marketing policies and strategies for antitobacco messages through all media.

\section{Author affiliations}

${ }^{1}$ School of Public Health, Tropical Medicine and Rehabilitation Sciences, James Cook University, Cairns, Queensland, Australia

${ }^{2}$ School of Health and Human Sciences, Southern Cross University, Coffs Harbour, New South Wales, Australia

${ }^{3}$ School of Public Health, Tropical Medicine and Rehabilitation Sciences, James Cook University, Townsville, Queensland, Australia

${ }^{4}$ Department of Epidemiology and Public Health, Health Behaviour Research Centre, University College London, London, UK

${ }^{5}$ School of Indigenous Australian Studies, James Cook University, Townsville, Queensland, Australia

${ }^{6}$ Australian Institute of Tropical Health and Medicine, James Cook University, Cairns, Queensland, Australia

Acknowledgements The authors acknowledge the valuable input of the Aboriginal community panel and the support of the partnering ACCHS for this survey, and role of the Aboriginal Health Worker in the study, without them the study would not be possible. 
Contributors GSG was responsible for the concept and design of the project, developing and adapting the survey instruments and digital format, testing the suitability of the survey for Indigenous participants, conducting surveys, training and supervising Indigenous research assistants to conduct surveys, collating and analysing and interpreting results, writing reports and manuscripts. KW contributed to the research design and statistical analysis and critical review of manuscripts. AM advised on any aspect relating to tobacco smoking, smoking risk behaviours, the survey and critical review of manuscripts. YC-J as Aboriginal academic advisor advised on the Indigenous community consultation processes, recruitment and the cultural interpretation of results. ARC oversaw the study and advised on all aspects, and provided critical review of manuscripts.

Funding This study was funded by the following grants awarded to GSG as principal researcher: National Health and Medical Research Council (Australia) and National Heart Foundation (Australia) post-graduate scholarship for Indigenous health research-APP1039759 and PP 11S 6181, Royal Australian College of General Practitioners and Australian Primary Health Care Research Institute Indigenous Health Award 2013, James Cook University, Faculty of Medicine, Health \& Molecular Sciences, Graduate Research Scheme grant 2013 and 2014, ARC holds a National Health and Medical Research Council Career Development Award (APP1046773).

Competing interests None.

Ethics approval Aboriginal Health and Medical Research Council Ethics Committee, Australia; James Cook University, Australia; Southern Cross University, Australia.

Provenance and peer review Not commissioned; externally peer reviewed.

Open Access This is an Open Access article distributed in accordance with the Creative Commons Attribution Non Commercial (CC BY-NC 3.0) license, which permits others to distribute, remix, adapt, build upon this work noncommercially, and license their derivative works on different terms, provided the original work is properly cited and the use is non-commercial. See: http:// creativecommons.org/licenses/by-nc/3.0/

\section{REFERENCES}

1. OECD. OECD Factbook 2013: economic, environmental and social statistics: smoking. OECD Publishing, 2013.

2. Baker A, Ivers RG, Bowman J, et al. Where there's smoke, there's fire: high prevalence of smoking among some sub-populations and recommendations for intervention. Drug Alcohol Rev 2006;25:85-96.

3. Vos T, Barker B, Stanley L, et al. The burden of disease and injury in Aboriginal and Torres Strait Islander peoples 2003. Brisbane: The University of Queensland, 2007.

4. Australian Bureau of Statistics. 4727.0.55.001-Australian Aboriginal and Torres Strait Islander Health Survey: first results, Australia, 2012-13. Canberra: Australian Bureau of Statistics, 2013 [cited 28 November 2013]. http://www.abs.gov.au/ausstats/abs@.nsf/Lookup/ 39E15DC7E770A144CA257C2F00145A66?opendocument.

5. Robertson J, Conigrave K, Ivers R, et al. Addressing high rates of smoking in remote Aboriginal communities: new evidence for GPs. Aust Fam Physician 2013;42:492-6.

6. Li Z, Zeki R, Hilder L, et al. Australia's mothers and babies 2010. In: National Perinatal Epidemiology and Statistics Unit, ed. Sydney: Australian Institute of Health and Welfare; 2011. Canberra: Australian Institute of Health and Welfare (AIHW) National Perinatal Epidemiology and Statistics Unit, 2012.

7. DiGiacomo M, Davidson PM, Abbott PA, et al. Smoking cessation in indigenous populations of Australia, New Zealand, Canada, and the United States: elements of effective interventions. Int J Environ Res Public Health 2011;8:388-410.

8. Freemantle J, Officer K, McAullay D, et al. Australian indigenous health-within an international context. Darwin: Cooperative Research Centre for Aboriginal Health, 2007.

9. Carson KV, Robertson TA, Brinn MP, et al. Tobacco use, cessation and prevention for Indigenous populations: review of current evidence and future perspectives. In: Jackson OT, Evans KA. ed. Health disparities: epidemiology racial/ethnic and socioeconomic risk factors and strategies for elimination. New York: Nova Science Publishers, 2013:1-38.

10. Brady M. Historical and cultural roots of tobacco use among Aboriginal and Torres Strait Island people. Aust NZ J Public Health 2002;26:120-4.
11. Thomas DP, Briggs V, Anderson I, et al. The social determinants of being an Indigenous non-smoker. Aust NZ J Public Health 2008;32:110-16.

12. Paradies $\mathrm{Y}$, Harris $\mathrm{R}$, Anderson I. The impact of racism on indigenous health in Australia and Aotearoa: towards a research agenda. Discussion Paper No. 4. Darwin: Cooperative Research Centre for Aboriginal Health; 2008.

13. Gould GS, Munn J, Watters T, et al. Knowledge and views about maternal tobacco smoking and barriers for cessation in Aboriginal and Torres Strait Islanders: a systematic review and meta-ethnography. Nicotine Tob Res 2013;15:863-74.

14. Johnston V, Thomas DP. Smoking behaviours in a remote Australian Indigenous community: the influence of family and other factors. Soc Sci Med 2008;67:1708-16.

15. Passey M, Gale JT, Sanson-Fisher RW. 'It's almost expected': rural Australian Aboriginal women's reflections on smoking initiation and maintenance: a qualitative study. BMC Womens Health 2011;11:55.

16. Winstanley M, van der Sterren A, Knoche D. Chapter 8. Tobacco use among Aboriginal peoples and Torres Strait Islanders. In: Scollo MMWinstanley MH. eds. Tobacco in Australia: facts and issues. 4th edn. Melbourne: Cancer Council Victoria, 2012:48.

17. Johnston F, Beecham R, Dalgleish P, et al. The Maningrida: 'Be Smoke Free' project. Health Promot J Austr 1998;8:12-17.

18. Zuo Y, Minniecon S, Hua M. 'If you want your life to end bad, go ahead and smoke': a focus group study of Aboriginal and Torres Strait Islander young people's attitudes and knowledge towards smoking. Health Promot J Austr 2004;15:82-3.

19. Stewart HS, Bowden JA, Bayly MC, et al. Potential effectiveness of specific anti-smoking mass media advertisements among Australian Indigenous smokers. Health Educ Res 2011;26:961-75.

20. Gould GS, Watt K, Stevenson L, et al. Developing anti-tobacco messages for Australian Aboriginal and Torres Strait Islander peoples: evidence from a national cross-sectional survey. BMC Public Health 2014;14:250.

21. Boyle T, Shepherd CCJ, Pearson G, et al. Awareness and impact of the 'Bubblewrap' advertising campaign among Aboriginal smokers in Western Australia. Tob Control 2010;19:83-6.

22. Ivers R, Castro A, Parfitt D, et al. Television and delivery of health promotion programs to remote Aboriginal communities. Health Promot J Austr 2005;16:155-8.

23. Vogeltanz-Holm N, Holm J, White Plume J, et al. Confirmed recall and perceived effectiveness of tobacco countermarketing media in rural youth. Prev Sci 2009;10:325-34.

24. Grigg M, Waa A, Bradbrook SK. Response to an Indigenous smoking cessation media campaign: it's about whanau. Aust NZ J Public Health 2008;32:559-64.

25. Gould GS, McEwen A, Watters T, et al. Should anti-tobacco media messages be culturally targeted for Indigenous populations? A systematic review and narrative synthesis. Tob Control 2013;22:e7.

26. Australian Government. Indigenous Anti-Smoking Campaign: Break the Chain-Quantitative Campaign Effectiveness: ResearchExecutive Summary. Secondary Indigenous Anti-Smoking Campaign: Break the Chain-Quantitative Campaign Effectiveness: Research-Executive Summary 30 May 2012 October 2011. http:// www.quitnow.gov.au/internet/quitnow/publishing.nsf/Content/ ntc-break-the-chain

27. Bramley D, Riddell T, Whittaker R, et al. Smoking cessation using mobile phone text messaging is as effective in Maori as non-Maori. N Z Med J 2005;118:1216.

28. Wood L, France $\mathrm{K}$, Hunt $\mathrm{K}$, et al. Indigenous women and smoking during pregnancy: knowledge, cultural contexts and barriers to cessation. Soc Sci Med 2008;66:2378-89.

29. Gilligan C, Sanson-Fisher RW, D'Este C, et al. Knowledge and attitudes regarding smoking during pregnancy among Aboriginal and Torres Strait Islander women. Med J Aust 2009;190:557-61.

30. Passey M, Gale J, Holt B, et al. Stop smoking in its tracks: understanding smoking by rural Aboriginal women. The 10th National Rural Health Conference; Cairns, QLD, 2009.

31. Douglas TA, Buettner PG, Whitehall J. Maternal awareness of sudden infant death syndrome in North Queensland, Australia: an analysis of infant care practices. J Paediatr Child Health 2001;37:441-45.

32. Wilson G. What do Aboriginal women think is good antenatal care? Consultation report. Alice Springs, N T: Cooperative Research Centre for Aboriginal Health, 2009.

33. Heath DL, Panaretto K, Manessis V, et al. Factors to consider in smoking interventions for indigenous women. Aust J Prim Health 2006;12:131-6.

34. Gould GS, Munn J, Avuri S, et al. 'Nobody smokes in the house if there's a new baby in it': Aboriginal perspectives on tobacco smoking in pregnancy and in the household in regional NSW Australia. Women Birth 2013;26:246-53. 
35. Passey M, D'Este CA, Stirling JM, et al. Factors associated with antenatal smoking among Aboriginal and Torres Strait Islander women in two jurisdictions. Drug Alcohol Rev 2012;31:608-16.

36. Patten CA, Windsor RA, Renner CC, et al. Feasibility of a tobacco cessation intervention for pregnant Alaska Native women. Nicotine Tob Res 2010;12:79-87.

37. Ivers R. Anti-tobacco programs for Aboriginal and Torres Strait Islander people. In: AloHaW, ed. Closing the Gap Clearinghouse. Canberra: Australian Government, 2011:1 and 5.

38. Australian Department of Health and Ageing. Developmental Research to inform the National Action to Reduce Smoking Rates Social Marketing Campaign. 2010 [updated 7 Dec 2010, 20 November 2011]. http://www.health.gov.au/internet/ctg/publishing. nsf/Content/development-market-research

39. Witte K, Allen M. A meta-analysis of fear appeals: implications for effective public health campaigns. Health Educ Behav 2000;27:591-615.

40. Witte K, Cameron KA, McKeon JK, et al. Predicting risk behaviors: development and validation of a diagnostic scale. J Health Commun 1996;1:317.

41. Witte K, Meyer G, Martell D. Effective health risk messages: a step-by-step guide. Thousand Oaks, CA: Sage Publications, 2001.

42. Bandura A. Health promotion by social cognitive means. Health Educ Behav 2004;31:143-64.

43. Maloney EK, Lapinski MK, Witte K. Fear appeals and persuasion: a review and update of the Extended Parallel Process Model. Soc Personal Psychol Compass 2011;5:206-19.

44. Wong NCH, Cappella JN. Antismoking threat and efficacy appeals: effects on smoking cessation intentions for smokers with low and high readiness to quit. J Appl Commun Res 2009;37:1-20.

45. Guidry JJ, Fagan P, Walker V. Cultural sensitivity and readability of breast and prostate printed cancer education materials targeting African Americans. J Natl Med Assoc 1998;90:165-9.

46. Lee HS, Park JS. Cultural orientation and the persuasive effects of fear appeals: the case of anti-smoking public service announcements. J Med Mark 2012;12:73-80.

47. Murray-Johnson L, Witte K, Boulay M, et al. Using health education theories to explain behavior change: a cross-country analysis. Int $Q$ Community Health Educ 2006;25:185-207.

48. Muthusamy N, Levine TR, Weber R. Scaring the already scared: some problems With HIV/AIDS fear appeals in Namibia. J Commun 2009;59:317-44.

49. Smith RA, Ferrara M, Witte K. Social sides of health risks: stigma and collective efficacy. Health Commun 2007;21:55-64.

50. Sobre-Denton M, Hart D. Mind the gap: application-based analysis of cultural adjustment models. Int $J$ Intercult Relat 2008;32:538-52.

51. Terblanche-Smit M, Terblanche NS. Race and attitude formation in HIV/Aids fear advertising. J Bus Res 2010;63:121-5.

52. Witte K, Berkowitz JM, Lillie JM, et al. Radon awareness and reduction campaigns for African Americans: a theoretically based evaluation. Health Educ Behav 1998;25:284-303.

53. Witte K. A theoretically based evaluation of HIV/AIDS prevention campaigns along the trans-Africa highway in Kenya. $J$ Health Commun 1998:3:345-63.

54. West R. Theory of addiction. Oxford: Blackwell, 2006.

55. West R. The multiple facets of cigarette addiction and what they mean for encouraging and helping smokers to stop. COPD 2009;6:277-83.
56. Cattaruzza MS, West R. Why do doctors and medical students smoke when they must know how harmful it is? Eur $J$ Public Health 2013;23:188-9.

57. Berry J, Poortinga Y, Segall M, et al. Cross-cultural psychology: research and applications. Chapter 1: introduction to cross cultural psychology. 2nd edn. Cambridge: Cambridge University Press, 2002:1-15.

58. Drew N, Adams $\mathrm{Y}$, Walker R. Issues in mental health assessment with Indigenous Australians. In: Purdie N, Dudgeon P, Walker R, eds. Working together: Aboriginal and Torres Strait Islander mental health and wellbeing principles and practice. Canberra: Department of Health and Ageing, 2010:194-9.

59. Altman D. Practical statistics for medical research. London: Chapman and Hall, 1991.

60. Tabachnik BG, Fidel LS. Using multivariate statistics. 6th edn. Pearson, 2013.

61. ABS. National Aboriginal and Torres Strait Islander Social Survey 2008. Canberra: Australian Bureau of Statistics, 2009. http://www. abs.gov.au/ausstats/abs@.nsf/mf/4714.0/

62. Fidler J, Shahab L, West R. Strength of urges to smoke as a measure of severity of cigarette dependence: comparison with the Fagerstrom Test for nicotine dependence and its components. Addiction 2011;106:631-8.

63. Fidler JA, Shahab L, West O, et al. 'The smoking toolkit study': a national study of smoking and smoking cessation in England. BMC Public Health 2011;11:479.

64. Kotz D, Brown J, West R. Predictive validity of the Motivation To Stop Scale (MTSS): a single-item measure of motivation to stop smoking. Drug Alcohol Depend 2013;128:15-19.

65. Thomas DR. A general inductive approach for analyzing qualitative evaluation data. Am J Eval 2006;27:237-46.

66. NHMRC. Values and ethics: guidelines for ethical conduct in Aboriginal and Torres Strait Islander health research. Canberra, ACT: Commonwealth of Australia, 2003.

67. Centre for Health Advancement-Population Health Division. The NSW SmokeCheck Aboriginal Tobacco Prevention Project 20072008. Final report. NSW Department of Health, 2010.

68. Campbell S BI, Swinbourne A, Cadet-James Y, et al. Stages of change, smoking behaviour and readiness to quit in a large sample of Indigenous Australians living in eight remote North Queensland communities. Int J Environ Res Public Health 2013;10:1562-71.

69. Hettema JE, Hendricks PS. Motivational interviewing for smoking cessation: a meta-analytic review. J Consult Clin Psychol 2010;78:868-84.

70. Chamberlain C, O'Mara-Eves A, Oliver S, et al. Psychosocial interventions for supporting women to stop smoking in pregnancy. Cochrane Database Syst Rev 2013;(10):CD001055.

71. Passey M, D'Este CA, Sanson-Fisher R. Knowledge, attitudes and other factors associated with assessment of tobacco smoking among pregnant Aboriginal women by health care providers: a cross-sectional survey. BMC Public Health 2012;12:165.

72. Barry AE, Chaney B, Piazza-Gardner AK, et al. Validity and reliability reporting practices in the field of health education and behavior: a review of seven journals. Health Educ Behav 2013;2014;41:12-18.

73. Stephens A, Bohanna I, Graham D, et al. Screening and assessment instruments for use in Indigenous-specific alcohol and drug treatment rehabilitation. J Trop Psychol 2013;3/e2. doi:10.1017/ jtp.2013.2 